\title{
DISTINÇÃO (DISTINGUISHING) E CONFRONTO ANALÍTICO NO CABIMENTO DO RECURSO ESPECIAL POR DIVERGÊNCIA DE PRECEDENTES ${ }^{1}$
}

\section{DISTINGUISHING AND ANALYTICAL CONFRONTATION IN THE SPECIAL APPEAL BASED IN DIVERGENCE OF PRECEDENTS}

\author{
Rodrigo Pereira Moreira \\ Mestre em Direito pela Universidade Federal de \\ Uberlândia/MG. Professor de Direito da Universidade \\ Estadual de Goiás (Campus Morrinhos) e do ILES/ULBRA de \\ Itumbiara. Advogado. Itumbiara/GO. E-mail: \\ rodrigop.moreira@yahoo.com.br.
}

RESUMO: Este artigo possui como tema a análise das técnicas de distinção (distinguishing) e confronto analítico na hipótese de cabimento do recurso especial por divergência de precedentes entre tribunais. Como objetivo geral tem-se o estudo das técnicas de distinção e do confronto analítico que fundamentam o cabimento do recurso especial em caso de decisões divergentes entre tribunais de justiça do Brasil (Art. 105, III, "c" da Constituição Federal de 1988). Para se alcançar o objetivo geral proposto, é necessária a observação de três objetivos específicos: (i) analisar as funções atuais dos tribunais superiores; (ii) estudar as técnicas do distinguishing (distinção) e do confronto analítico como métodos de comparação de casos no recurso especial; (iii) verificar documentalmente, na jurisprudência do Superior Tribunal de Justiça, qual o entendimento desse tribunal a respeito da aplicação das referidas técnicas entre os anos de 2016 a 2019 (período de vigência do novo Código de Processo Civil). O método utilizado será o tópico-sistemático. A primeira parte abordará de forma sistemática a configuração do recurso especial. A segunda parte focará na análise de julgados do STJ em relação à hipótese de cabimento por divergência de precedentes.

\footnotetext{
${ }^{1}$ Artigo recebido em 31/08/2020 e aprovado em 16/11/2020.
} 
PALAVRAS-CHAVE: Precedentes Judiciais; Superior Tribunal de Justiça; Novo Código de Processo Civil; Constituição Federal.

\begin{abstract}
This paper has as its theme the analysis of the distinguishing and analytical confrontation in the appropriateness hypothesis of the special appeal by divergence between precedents of courts. The general objective is the study of the techniques of distinguishing and analytical confrontation that justify the appropriateness of the special appeal in case of divergent decisions between courts of law in Brazil (Article 105, III, "c" of the 1988 Federal Constitution). In order to achieve the general objective proposed it is necessary to observe three specific objectives: (i) to analyze the current functions of the higher courts; (ii) to study the techniques of distinguishing and analytical confrontation as methods of comparing cases in the special appeal; (iii) to verify, in the jurisprudence of the Superior Court of Justice, the Court's understanding regarding the application of these techniques between 2016 and 2018 (period of validity of the new Code of Civil Procedure). The method used will be topicsystematic. The first part will cover systematically setting up special appeal. The second part will focus on the analysis of cases of the STJ in relation to the hypothesis of divergence of precedents.
\end{abstract}

KEY WORDS: Judicial Precedents; Superior Court of Justice; New Code of Civil Procedure; Federal Constitution.

\title{
INTRODUÇÃ̃O ${ }^{2}$
}

O presente artigo possui como tema a hipótese de cabimento do recurso especial (dirigido ao Superior Tribunal de Justiça) nos casos de situações semelhantes em que os tribunais de justiça do Brasil tenham conferido interpretação divergente da lei federal. Essa questão está ligada com a necessidade de se garantir igualdade (casos semelhantes devem ser tratados de forma semelhante), segurança jurídica e integridade (art. 926, CPC/2015) na interpretação da lei em todo o território nacional, mas que, para ter aplicabilidade, o

\footnotetext{
${ }^{2}$ Agradeço ao Prof. Dr. Alexandre Bahia pela discussão prévia dos pressupostos teóricos deste artigo. Artigo elaborado dentro de projeto de pesquisa com o mesmo título desenvolvido na Universidade Estadual de Goiás.
} 
recorrente deverá demonstrar que os casos a serem analisados pelo Superior Tribunal de Justiça guardam semelhanças fáticas e jurídicas.

Atualmente, o Superior Tribunal de Justiça ganhou grande importância na uniformização da aplicação do Direito, principalmente a partir da perspectiva de observação dos precedentes judiciais (em sentido amplo) que, por sua vez, representam a aplicação de julgados anteriores a processos semelhantes. Assim, tomando como ponto de partida o recurso especial e a formação dos precedentes (em uma perspectiva de ônus argumentativo), inclui-se o estudo das técnicas da distinção (distinguishing) e do confronto analítico como meios de analisar se os casos a serem apreciados pelo tribunal possuem semelhanças fáticas e jurídicas que permitam a interposição do recurso especial.

O objetivo geral constitui-se no estudo das técnicas de distinção e confronto analítico que fundamentam o cabimento do recurso especial em caso de decisões divergentes entre tribunais de justiça do Brasil (Art. 105, III, “c” da Constituição Federal de 1988).

Para se alcançar o objetivo geral proposto é necessária a observação de três objetivos específicos: (i) analisar as funções atuais dos tribunais superiores, em especial a partir dos precedentes no novo Código de Processo Civil; (ii) estudar as técnicas do distinguishing (distinção) e do confronto analítico como métodos de comparação de casos no recurso especial; (iii) verificar na jurisprudência do Superior Tribunal de Justiça qual o entendimento desse tribunal a respeito da aplicação das referidas técnicas entre os anos de 2016 a 2019 (período de vigência do novo Código de Processo Civil).

O método utilizado será o tópico-sistemático. A primeira parte abordará, de forma sistemática, a configuração do recurso especial. A segunda parte focará na análise de julgados do STJ em relação à hipótese de cabimento por divergência de precedentes.

\section{O PAPEL DOS TRIBUNAIS SUPERIORES E O RECURSO ESPECIAL}

Os recursos especial e extraordinário, destinados respectivamente para 0 Superior Tribunal de Justiça (STJ) e para o Supremo Tribunal Federal (STF), não possuem as mesmas funções empregadas em recursos direcionados aos tribunais inferiores. Por serem órgãos de cúpula, esses dois tribunais detêm um caráter de uniformização da aplicação da lei federal e da Constituição Federal de 1988 em todo o território nacional. 
Primeiramente, é importante apontar a tese que entende os tribunais superiores como cortes de vértice cuja formação de precedentes são formalmente vinculantes pelo fato de terem sido emanados de determinados órgãos do Poder Judiciário.

Para Daniel Mitidiero, é preciso que determinadas cortes sejam vocacionadas a resolver o caso concreto de forma justa enquanto outras cortes possuem a função de formar precedentes judiciais. Assim, existem as chamadas Cortes de Justiça e Cortes de Precedentes. As primeiras devem tutelar os direitos mediante uma decisão justa. As segundas utilizam o caso concreto como pretexto (um meio) para interpretar as normas e criar o precedente judicial. $^{3}$

As Cortes de Precedentes podem estar vinculadas a dois modelos: Cortes Superiores e Cortes Supremas. Aquelas partem de uma perspectiva cognitivista do Direito em que se declara no julgado uma norma pré-existente com o objetivo de controlar as decisões judiciais por meio de jurisprudência uniforme. Estas pressupõem uma visão não cognitivista do Direito em que a decisão judicial implica uma reconstrução e outorga de sentido aos textos normativos, criando precedentes para serem aplicados aos casos posteriores. ${ }^{4}$ O Supremo Tribunal Federal e o Superior Tribunal de Justiça seguiriam o modelo de Cortes Supremas na medida em que sua função mais importante é interpretar e criar os precedentes vinculantes que deverão ser obrigatoriamente seguidos pelos tribunais inferiores. $^{5}$

No mesmo sentido, está a perspectiva de Luiz Guilherme Marinoni. Para esse autor, a função do Superior Tribunal de Justiça é identificar no texto legal a norma jurídica que está de acordo com a sociedade e o Estado a partir da apresentação das melhores razões para tanto. Suas decisões passam a constituir o ordenamento jurídico por meio de precedentes obrigatórios. ${ }^{6}$

\footnotetext{
${ }^{3}$ MITIDIERO, Daniel. Cortes Superiores e Cortes Supremas: do controle à interpretação, da jurisprudência ao precedente. $3^{\text {a }}$ ed. São Paulo: Revista dos Tribunais, 2017, p. 37-39.

${ }^{4}$ MITIDIERO, Daniel. Cortes Superiores e Cortes Supremas: do controle à interpretação, da jurisprudência ao precedente. $3^{\text {a }}$ ed. São Paulo: Revista dos Tribunais, 2017, p. 39-40.

${ }^{5}$ MITIDIERO, Daniel. Cortes Superiores e Cortes Supremas: do controle à interpretação, da jurisprudência ao precedente. $3^{a}$ ed. São Paulo: Revista dos Tribunais, 2017, p. 111-112. Continua o autor: "A violação à interpretação ofertada pelo Supremo Tribunal Federal e pelo Superior Tribunal de Justiça é uma insubordinação institucional da mais alta gravidade no Estado Constitucional”.

${ }^{6}$ MARINONI, Luiz Guilherme. O STJ enquanto cortes de precedentes. $2^{\mathrm{a}}$ ed. São Paulo: Revista dos Tribunais, 2014, p. 77. No sentido de precedentes formalmente vinculantes independentemente do seu conteúdo, veja-se: ZANETI JR., Hermes. Precedentes (treat like cases alike) e o novo Código de Processo Civil: universalização e vinculação horizontal como critérios de racionalidade e a negação da "jurisprudência persuasiva" como base
} 
Não obstante a força argumentativa dessa tese, é importante notar que esse posicionamento aumenta de forma preocupante a quantidade de precedentes obrigatórios ao criar um modelo ultraestatalista que esvazia o papel da Cidadania e não pode ser aceito em um Estado Constitucional Democrático de Direito. ${ }^{7}$ Sob a lógica dos precedentes obrigatórios, quando emanados de Cortes Supremas, pouco importa se a decisão tomada foi correta ou não ${ }^{8}$ e isso pode implicar graves problemas para a aplicação do Direito. Veja-se, por exemplo, a questão da prisão em segunda instância e o Supremo Tribunal Federal.

Além disso, entender que a função das Cortes Supremas é interpretar o texto normativo construindo o sentido da norma e que os demais tribunais (e juízes inferiores) devem apenas aplicar aquilo que foi decidido é um retorno a uma espécie de realismo jurídico, ou seja, entender que o Direito é aquilo que os tribunais superiores dizem ser. $\mathrm{O}$ que constitui um agravante, pois o juiz de primeira instância seria relegado a ser apenas um juiz "boca dos precedentes judiciais", mesmo quando estes forem contrários à lei ou à Constituição Federal, ${ }^{9}$ criando uma espécie de nova Escola da Exegese. ${ }^{10}$

A identificação da força obrigatória do precedente na sua razão de decidir (ratio decidendi) implica uma contradição em termos explicada por Aurélio Viana e Dierle Nunes: "Se as cortes e os juízes de grau inferior podem interpretar a ratio decidendi, por conseguinte poderão também divergir em relação ao próprio precedente, uma vez que o seu núcleo é exatamente a ratio. Se a ratio decidendi não é vinculante, não há como o precedente sê-lo. Reside nisso o paradoxo! Como falar em precedente obrigatório se o seu núcleo - a ratio

para uma teoria dogmática dos precedentes no Brasil. Revista de Processo, vol. 235, p. 293-349, set., 2014 [recurso eletrônico]; ZANETI JR., Hermes. O valor vinculante dos precedentes: teoria dos precedentes normativos formalmente vinculantes. $2^{a}$ ed. Salvador: Juspodivm, 2016, p. 323-324.

${ }^{7}$ VIANA, Aurélio; NUNES, Dierle. Precedentes: a mutação do ônus argumentativo. Rio de Janeiro: Forense, 2018, p. 248. Aqui é importante notar que já fomos adeptos da teoria formalmente vinculante dos precedentes judiciais (mesmo com alguns temperamentos sobre a questão interpretativa). No entanto, após os diversos problemas ocorridos com julgados do Supremo Tribunal Federal, em decisões flagrantemente contrárias à própria Constituição Federal, mudamos o nosso entendimento.

${ }^{8}$ VIANA, Aurélio; NUNES, Dierle. Precedentes: a mutação do ônus argumentativo. Rio de Janeiro: Forense, 2018, p. 252.

${ }^{9}$ STRECK, Lenio Luiz. Precedentes Judiciais e Hermenêutica: o sentido da vinculação no CPC/2015. $2^{\mathrm{a}}$ ed. Salvador: Juspodivm, 2019.

${ }^{10}$ BAHIA, Alexandre. As súmulas vinculantes e a nova Escola da Exegese. Revista de Processo, ano 37, vol. 206, p. 359-379, abril, 2012. Nas palavras do autor: "A Exegese foi uma corrente do pensamento jurídico no século XIX que acreditava na clareza dos textos jurídicos e na segurança jurídica que daí advinha. Acreditavase no poder absoluto da razão, que, compartilhada igualmente por todos, tornaria óbvias as normas de agir”. 
decidendi - encontra-se em estado de permanente abertura à interpretação pelas cortes inferiores?". ${ }^{11}$

Destarte, não é possível entender o precedente como obrigatório em razão da sua origem. Como veremos mais adiante, a utilização do precedente carrega consigo um ônus argumentativo que determina uma interpretação dos juízes e tribunais para entender os fatos, a ratio decidendi e a sua possível aplicação nos casos concretos. Dessa forma, o modelo de Cortes Supremas formadoras de precedentes vinculantes não se enquadra no modelo constitucional brasileiro. O Superior Tribunal de Justiça e o Supremo Tribunal Federal formam precedentes judiciais, mas isso é algo construído a partir de uma interpretação posterior e realizada por aquele que, ao mesmo tempo, aplica e interpreta o julgado.

Em relação aos recursos que fazem com que casos cheguem aos tribunais superiores, Teresa Arruda Alvim e Bruno Dantas lecionam que estes possuem as seguintes funções: (i) função nomofilática, consubstanciada no interesse do Estado em julgar o recurso para aplicar corretamente a legislação; (ii) função uniformizadora, haja vista que os recursos julgados pelos tribunais superiores devem ser aplicados como precedentes para outros casos similares, garantindo que casos suficientemente idênticos produzam os mesmos efeitos jurídicos; (iii) função dikelógica, pois as partes processuais possuem o interesse de ver julgado o recurso a seu favor; (iv) função paradigmática, levando em consideração que as decisões proferidas pelos tribunais superiores devem servir como modelo para as decisões dos tribunais inferiores. ${ }^{12}$

\footnotetext{
${ }^{11}$ VIANA, Aurélio; NUNES, Dierle. Precedentes: a mutação do ônus argumentativo. Rio de Janeiro: Forense, 2018, p. 257. Sobre a conceituação de ratio decidendi e obter dictum afirma Rodrigo Ramina de Lucca: "Em apertada síntese, a ratio decidendi é a efetiva razão jurídica pela qual o magistrado decide; e o obter dictum que significa 'o que é dito de passagem', é composto por considerações acessórias, por vezes supérfluas, por vezes relevantes, mas que não representam a razão jurídica acolhida pelo magistrado" (LUCCA, Rodrigo Ramina de. O conceito de precedente judicial, ratio decidendi e a universalidade das razões jurídicas de uma decisão. In: NUNES, Dierle; MENDES, Aluisio; JAYME, Fernando Gonzaga (org.). A nova aplicação da jurisprudência e precedentes no CPC/2015. São Paulo: Revista dos Tribunais, 2017, p. 956).

${ }^{12}$ ALVIM, Teresa Arruda; DANTAS, Bruno. Recurso especial, recurso extraordinário e a nova função dos tribunais superiores no direito brasileiro. $4^{\mathrm{a}}$ ed. São Paulo: Revista dos Tribunais, 2017, p. 308-328. Aqui é importante notar que os autores entendem que são obrigatórios apenas os precedentes incluídos no art. 927 do CPC/2015, ressalvando ainda que nem todos os incisos do artigo refletem verdadeiros precedentes, na medida em que súmulas e precedentes são institutos distintos. Sobre essas funções vide ainda: MEDINA, José Miguel Garcia. Prequestionamento, repercussão geral da questão constitucional, relevância da questão federal: admissibilidade, processamento e julgamento dos recursos extraordinário e especial. $7^{\text {a }}$ ed. São Paulo: Revista dos Tribunais, 2017, p. 28-32. WEBER, Márcia Regina Lusa Cadore. Anotações sobre os recursos especial e extraordinário. Revista dos Tribunais, Vol. 820, p. 98-124, São Paulo, Fev., 2004 [recurso eletrônico].
} 
Dentre essas funções, geralmente, é ressaltado que aos tribunais superiores cabe uma função predominantemente pública, focada, pois, na definição do direito objetivo. A função privada de julgar casos seria apenas reflexa. ${ }^{13}$

Em contrapartida, como assevera Alexandre Bahia, apesar de os recursos especial e extraordinário possuírem uma dimensão pública consistente na uniformização da jurisprudência e afirmação da autoridade constitucional, esta não é a única função e nem a mais importante. Os julgados dos tribunais superiores em sede recursal não devem formar “teses", mas resolver os casos que lhes são apresentados. ${ }^{14}$

Assim, não se pode negar a importância do estudo recurso especial no intuito de garantir a aplicação correta de normas federais infraconstitucionais e a uniformização de sua interpretação a partir da função paradigmática. No entanto, não significa que isso deve se realizar por meio da construção de precedentes vinculantes. A força do precedente é construída com base na sua argumentação, interpretação e aplicação aos casos posteriores.

O recurso especial é previsto no art. 105, III da Constituição Federal que assim afirma: “Art. 105. Compete ao Superior Tribunal de Justiça: [...] III - julgar, em recurso especial, as causas decididas, em única ou última instância, pelos Tribunais Regionais Federais ou pelos tribunais dos Estados, do Distrito Federal e Territórios, quando a decisão recorrida: a) contrariar tratado ou lei federal, ou negar-lhes vigência; b) julgar válido ato de governo local contestado em face de lei federal; c) der a lei federal interpretação divergente da que lhe haja atribuído outro tribunal".

Como se pode perceber, o recurso especial possui três hipóteses de cabimento, ou seja, existem três possibilidades que permitem às partes manejarem esse recurso para o Superior Tribunal de Justiça. O foco do presente artigo é o estudo da hipótese retratada na alínea "c", cabível quando casos semelhantes forem decididos de forma diferente pelos tribunais estaduais ou federais espalhados pelo território brasileiro.

Antes da análise da utilização da distinção e do confronto analítico como ônus argumentativo do cabimento do recurso especial, é preciso explicar alguns conceitos básicos que permitirão uma melhor compreensão do tema.

\footnotetext{
${ }^{13}$ MEDINA, José Miguel Garcia. Prequestionamento, repercussão geral da questão constitucional, relevância da questão federal: admissibilidade, processamento e julgamento dos recursos extraordinário e especial. $7^{\mathrm{a}} \mathrm{ed}$. São Paulo: Revista dos Tribunais, 2017, p. 34.

${ }^{14}$ BAHIA, Alexandre Melo Franco. Recursos extraordinários no STF e no STJ. $2^{\mathrm{a}}$ ed. Curitiba: Juruá, 2016, p. 221.
} 


\section{SÚMULA, JURISPRUDÊNCIA E PRECEDENTES JUDICIAIS}

É comum utilizar as expressões "dissídio jurisprudencial" e "divergência jurisprudencial" para nomear a hipótese de cabimento do recurso especial quando tribunais divergem na interpretação da lei federal. No entanto, faz-se mister esclarecer que, apesar de próximos, os conceitos de súmula, jurisprudência e precedentes judiciais não se confundem.

Como desdobramento da sua teoria que distingue Cortes de Justiça e Cortes Supremas, Daniel Mitidiero afirma que os tribunais de justiça produzem apenas jurisprudência, enquanto o Supremo Tribunal Federal e o Superior Tribunal de Justiça formam os precedentes judiciais. A jurisprudência deriva da reiteração dos julgados de um tribunal de justiça que geram uniformidade. Os precedentes, por sua vez, são as razões de decidir generalizáveis identificadas a partir de decisões judiciais e que vinculam tanto os tribunais hierarquicamente inferiores (eficácia vertical) quanto os próprios tribunais superiores (eficácia horizontal). ${ }^{15}$

Como visto, essa distinção é complicada na medida em que parte de uma base teórica que amplia a vinculatividade do precedente independentemente do seu conteúdo. Dessa maneira, é preciso insistir em outros critérios que possam distinguir o precedente da jurisprudência.

Para Michele Taruffo: "o precedente fornece uma regra (universalizável, como já foi dito) que pode ser aplicada como critério de decisão no caso sucessivo em função da identidade ou - como acontece em regra - da analogia entre os fatos do primeiro caso e os fatos do segundo caso". ${ }^{16}$ Em outro viés, partindo das ideias do giro linguístico de Gadamer, Juraci Mourão Lopes Filho sustenta que o precedente é uma resposta institucional que determina um ganho de sentido para a norma jurídica aplicada na medida em que dele podem surgir novos sentidos para a prescrição jurídica, a escolha de um sentido dentre vários possíveis ou o avanço no tratamento de questões não detalhadas nos textos normativos. ${ }^{17}$

\footnotetext{
${ }^{15}$ MITIDIERO, Daniel. Precedentes, jurisprudência e súmulas no novo Código de Processo Civil brasileiro. Revista de Processo, vol. 245, p. 333-349, julho, 2015 [recurso eletrônico].

${ }^{16}$ TARUFFO, Michele. Precedente e jurisprudência. Revista de Processo. Vol. 29, p. 199-208, São Paulo, set., 2011 [recurso eletrônico]. Disponível em: www.revistadostribunais.com.br. Acesso em: 10.05.2017.

${ }^{17}$ LOPES FILHO, Juraci Mourão. Os precedentes judiciais no constitucionalismo brasileiro contemporâneo. $2^{\mathrm{a}}$ ed. Salvador: Juspodivm, 2016, p. 275.
} 
Nesse ponto, adotar-se-á o entendimento que em uma perspectiva ampla (lato sensu) o precedente é uma decisão anterior que pode ser utilizada para fundamentar decisões futuras. De forma restrita, o precedente é constituído pela sua razão de decidir (ratio decidendi) e funciona como um ponto inicial de argumentação para fundamentar outras decisões judiciais. A utilização de um precedente caracteriza um ônus argumentativo para a identificação das razões de decidir utilizadas no julgado e sua posterior aplicação em um caso semelhante. ${ }^{18}$ Não existe uma obrigatoriedade inerente ao precedente, mas apenas advinda de um processo de aplicação e interpretação dos fatos e da ratio decidendi.

A importância desta posição está na compreensão de que o precedente também exige interpretação. ${ }^{19}$ A aplicação de um precedente exigirá uma dupla interpretação: (i) a interpretação dos fatos para encontrar o precedente aplicável ao caso similar; (ii) a interpretação das próprias razões de decidir para descobrir a norma generalizável do precedente que possa ser aplicada aos casos posteriores.

Assim, a diferença entre precedente e jurisprudência não está no seu nascedouro, mas reside em um ponto quantitativo. A partir desse ponto de vista, a jurisprudência é um conjunto de julgados enquanto o precedente se refere à decisão de um caso particular. ${ }^{20}$

A súmula também não pode ser confundida com o precedente. As súmulas são extratos identificados em reiteradas decisões judiciais. Para ser aplicada, a súmula precisa ser interpretada a partir dos precedentes que permitiram a sua criação. ${ }^{21}$ Nessa direção, o art. $926, \S 2^{\circ}$ do $\mathrm{CPC} / 2015$ determina que, ao editar as súmulas, os tribunais devem atender às circunstâncias de fato que permitiram a sua edição. Nesse diapasão, ao se interpretar e aplicar uma súmula, a decisão judicial também deve se ater aos casos concretos que foram considerados pelo tribunal para criá-la.

\footnotetext{
${ }^{18}$ VIANA, Aurélio; NUNES, Dierle. Precedentes: a mutação do ônus argumentativo. Rio de Janeiro: Forense, 2018, p. 414. Em outras palavras: “[...] no common law parecedentes são starting points (principium) dos fundamentos jurídicos que venham trazer, ou seja, um julgado (ou conjunto deles) somente se tornará precedente se em aplicação analógica futura se verificar que seus fundamentos determinantes se aplicam ao caso futuro devido às identidades jurídicas e fáticas. O precedente no common law é um ponto de partida quando de modo recorrente entre nós é visto como ponto de chegada." (NUNES, Dierle; Bahia, Alexandre; PEDRON, Flávio Quinaud. Teoria geral do processo. Salvador: Juspodivm, 2020, p. 696-697).

${ }^{19}$ ABBOUD, Georges. Do genuíno precedente do stare decisis ao precedente brasileiro: os fatores histórico, hermenêutico e democrático que os diferenciam. In: DIDIER JÚNIOR, Fredie; et al. (coordenadores). Precedentes. Salvador: Juspodivm, 2015, p. 405.

${ }^{20}$ VIANA, Aurélio; NUNES, Dierle. Precedentes: a mutação do ônus argumentativo. Rio de Janeiro: Forense, 2018, p. 205.

${ }^{21}$ BAHIA, Alexandre Melo Franco. Recursos extraordinários no STF e no STJ. 2a ed. Curitiba: Juruá, 2016, p. 254 .
} 
Realizadas essas distinções necessárias e partindo da concepção de precedente em sentido lato, é possível entender que o cabimento do recurso especial por divergência jurisprudencial na verdade representa uma divergência entre precedentes judiciais. A comparação exigida entre julgados de tribunais diferentes constitui um típico raciocínio de interpretação e aplicação de precedentes na medida em que é composto pela analogia entre o caso em análise e o julgado paradigma de outro tribunal.

A técnica de comparação entre os precedentes para o cabimento do recurso especial, nos termos do art. 105, III, "c" da Constituição, é chamada de confronto analítico. O seu afastamento pode ocorrer por meio da distinção (distinguishing), ambas analisadas no próximo tópico.

\section{DISTINÇÃO E CONFRONTO ANALÍTICO NO RECURSO ESPECIAL POR DIVERGÊNCIA DE PRECEDENTES}

Em uma perspectiva formal, o cabimento do recurso especial depende do esgotamento de todas as instâncias recursais inferiores, ${ }^{22}$ podendo ser interposto contra a última decisão de algum tribunal de justiça (estadual ou federal), ${ }^{23}$ não sendo cabível de decisão relacionada à turma recursal de juizado especial regulado pela Lei 9.099/95.

Em uma visão material, o recurso especial pela alínea "c" do art. 105, III da CF/88 denota a necessidade de uniformizar a interpretação e aplicação da legislação federal, ${ }^{24}$ pois tribunais diferentes devem conceder uma mesma interpretação da lei quando os fatos forem semelhantes, sob pena de incorrer em violação do princípio da igualdade (casos semelhantes devem ser decididos de maneira semelhante).

Nesse ponto, é preciso afirmar que o recorrente, baseando-se nessa hipótese de cabimento, deverá formar o seu recurso de maneira a comprovar que a decisão proferida em outro tribunal da federação (acórdão paradigma) é diferente daquela conferida ao processo

\footnotetext{
22 WEBER, Márcia Regina Lusa Cadore. Anotações sobre os recursos especial e extraordinário. Revista dos Tribunais, Vol. 820, p. 98-124, São Paulo, Fev., 2004 [recurso eletrônico]. Disponível em: www.revistadostribunais.com.br. Acesso em: 02.10.2017.

${ }^{23}$ CARNEIRO, Athos Gusmão. Anotações sobre o recurso especial. Doutrinas Essenciais de Processo Civil, Vol. 7, p. 361-374, São Paulo, out., 2011 [recurso eletrônico]. Disponível em: www.revistadostribunais.com.br. Acesso em: 02.10.2017.

${ }^{24}$ TEIXEIRA, Sálvio de Figueiredo. O recurso especial e o Superior Tribunal de Justiça. Doutrinas Essenciais de Processo Civil, Vol. 7, p. 347-360, São Paulo, out., 2011 [recurso eletrônico].
} 
em que o recurso será interposto. Dessa maneira, é imperativo demonstrar que os casos entre os dois julgados são semelhantes e que as decisões são divergentes.

Nas palavras de Fredie Didier Júnior e Leonardo Carneiro da Cunha: “em qualquer caso, cabe ao recorrente mencionar 'as circunstâncias que identifiquem ou assemelhem os casos confrontados' (art. 1.029, $\S 1^{\circ}$, parte final, CPC). É o que a praxe forense convencionou denominar de confronto ou cotejo analítico entre o acórdão recorrido e o acórdão paradigma. Em outras palavras, não é suficiente para comprovar o dissídio jurisprudencial, a simples transcrição de ementas, sendo necessário que o recorrente transcreva trechos do relatório do acórdão paradigma e, depois, transcreva trechos do relatório do acórdão recorrido, comparando-os, a fim de demonstrar que ambos trataram de casos bem parecidos, ou cuja base fática seja bem similar. Após isso, deve o recorrente prosseguir no cotejo analítico, transcrevendo trechos do voto do acórdão paradigma e trechos do voto do acórdão recorrido para, então, confrontá-los, demonstrando que foram adotadas teses opostas. Trata-se, pois, de proceder ao método do distinguishing, a comparação entre o precedente invocado e a decisão recorrida $[. .] "$.

Assim, percebe-se que a argumentação em torno do recurso especial por divergência de precedentes estaduais ou federais deve ser realizada de maneira minuciosa e analítica para fim de demonstrar a similitude dos casos, bem como o entendimento diferente relacionado à interpretação de determinado dispositivo legal.

Essa demonstração deve ser realizada de maneira clara e objetiva, pois o não cumprimento desse requisito pode levar à inadmissão do recurso especial. ${ }^{26} \mathrm{O}$ mero copiar e colar ementas dos julgados tidos como divergentes não é o suficiente para a concretização do confronto analítico de precedentes.

Isso porque ementa não representa o precedente judicial. A ementa não integra a decisão colegiada na medida em que representa um mero resumo do julgamento. Se houver divergência entre a ementa e fundamentos dos votos, devem prevalecer os votos. ${ }^{27}$ Destarte,

\footnotetext{
${ }^{25}$ DIDIER JÚNIOR, Fredie; CUNHA, Leonardo Carneiro da. Curso de direito processual civil: meios de impugnação às decisões e processo nos tribunais. $13^{\mathrm{a}}$ ed. Salvador: Juspodivm, 2016, p. 348. No mesmo sentido: BAHIA, Alexandre Melo Franco. Recursos extraordinários no STF e no STJ. 2a ed. Curitiba: Juruá, 2016, p. 163.

${ }^{26}$ BRUSCHI, Gilberto Gomes. Recurso especial fundado em divergência jurisprudencial. Revista de Processo, vol. 148, p. 119-133, São Paulo, jun., 2007 [recurso eletrônico].

${ }^{27}$ MAGALHÃES, Breno Baía; SILVA, Sandoval Alves da. Quem vê ementa, não vê precedente: ementismo e precedentes judiciais no projeto do CPC. In: FREIRE, Alexandre; et all (org.) Novas tendências do processo civil: estudos sobre o projeto do novo Código de Processo Civil. Salvador: Juspodivm, 2014. V. II. Nas palavras
} 
existe a necessidade da comparação entre o precedente invocado e o acórdão recorrido ser conduzida a partir do interior teor dos julgados e não em relação às ementas. É preciso comparar os fatos e indicar a divergência de interpretação a respeito de um mesmo dispositivo de legislação federal.

Corroborando esse entendimento, Gilberto Bruschi explica que "a análise do dissídio deverá ser feita pela transcrição dos trechos dos acórdãos confrontados, evidenciando as circunstâncias que os identifiquem ou os assemelhem. Em outras palavras, há necessidade da demonstração de que a decisão recorrida cuida de situação fático-jurídica semelhante ao acórdão oferecido como paradigma e que, entretanto, as decisões foram diametralmente opostas nos casos confrontados, sustentando as razões pelas quais entende que a interpretação correta é a do acórdão divergente e não àquela proferida pelo tribunal $a$ quo." 28

Nesse diapasão, verifica-se que a hipótese de cabimento do recurso especial por divergência está intrinsicamente relacionada com a teoria dos precedentes em razão da similitude do raciocínio analógico para a identificação de casos semelhantes e aplicação do Direito ao caso concreto.

$\mathrm{Na}$ aplicação dos precedentes, é necessária a utilização de quatro passos. $\mathrm{O}$ primeiro consiste em analisar os casos dentro das suas circunstâncias fáticas e jurídicas. $\mathrm{O}$ segundo determina a verificação de semelhanças e diferenças entre os casos analisados. No terceiro passo, o julgador irá extrair do precedente as razões de decidir. No quarto e último passo, o magistrado irá concluir pela aplicação ou inaplicação do precedente ao analisar se será caso de distinção ou superação do precedente. ${ }^{29}$

É dessa perspectiva que resulta a necessidade de estudar de forma aprofundada a relação entre o confronto analítico e a técnica de distinção, esta última derivada da teoria dos precedentes judiciais. Essa atividade, contudo, não é simples como parece ser em um primeiro momento. Isso porque, na análise do cabimento por divergência, é dificultoso definir quando existe verdadeira semelhança entre os casos julgados por tribunais diferentes.

dos autores: “[...] a ementa não pode desempenhar nenhum papel jurídico relevante na compreensão do precedente, a não ser o de mera catalogação e de facilitar o acesso a ele, portanto, é impossível julgar casos com base, simplesmente, na citação da ementa de um acórdão".

${ }^{28}$ Ibidem, p. 128.

${ }^{29}$ FENSTERSEIFER, Wagner Arnold. Distinguinshing e overruling na aplicação do Art. 489, § $1^{\circ}$, VI, do CPC/2015. Revista de Processo, vol. 252, p. 371-385, São Paulo, fev., 2016 [recurso eletrônico]. 
Para solucionar tal questão, surgiram na Ciência do Direito duas teorias sobre a aplicação de julgados para casos iguais ou semelhantes.

A teoria da identidade absoluta determina que o confronto entre decisões (precedentes) só pode ser realizado quando os casos apresentam exatamente as mesmas características. ${ }^{30}$ No entanto, essa teoria não leva em consideração que, identificar casos exatamente iguais, é uma tarefa praticamente impossível, pois sempre haverá uma diferença entre as partes e pormenores que, muitas vezes, não afetam a solução final do caso (por exemplo: o sexo e a idade das pessoas envolvidas).

Posteriormente, surgiu a teoria da identidade essencial, a qual preconiza que os fatos analisados não precisam ser exatamente iguais, desde que os elementos essenciais da questão sejam os mesmos. No cabimento do recurso especial, o Superior Tribunal de Justiça deve-se ater à identidade essencial dos $\operatorname{casos},{ }^{31}$ até porque, se houver uma identidade material (fática) e uma identidade jurídica, estar-se-á diante da coisa julgada e não da aplicação de determinado precedente. ${ }^{32}$

Assim, no confronto analítico entre decisões divergentes, o recorrente deve argumentar a respeito da identidade essencial entre os casos analisados para ter o seu recurso avaliado pelo Superior Tribunal de Justiça. Por outro lado, poderá o julgador do processo ou a parte recorrida demonstrarem oportunamente que os julgados em questão são diferentes. Nessa hipótese, estar-se-á diante de uma distinção (distinguishing).

Sobre a distinção, Daniel Mitidiero explica que: "aplicar um precedente envolve, portanto, comparação entre casos. Não por outra razão normalmente se alude à analogia como elemento essencial o raciocínio jurídico de um sistema de precedentes. Em outras palavras, demanda a individualização dos pressupostos fático-jurídicos essenciais que dão vida aos casos e a busca por semelhanças ou distinções relevantes". ${ }^{33}$

Não havendo semelhança capaz de determinar a aplicação do precedente, será caso de o julgador utilizar a técnica do distinguishing ${ }^{34}$. A distinção ocorre quando se verifica

\footnotetext{
${ }^{30}$ ALVIM, Teresa Arruda; DANTAS, Bruno. Recurso especial, recurso extraordinário e a nova função dos tribunais superiores no direito brasileiro. $4^{\mathrm{a}}$ ed. São Paulo: Revista dos Tribunais, 2017, p. 198.

${ }^{31}$ Ibidem, p. 209.

32 ABBOUD, George. Súmula vinculante versus precedentes: notas para evitar alguns enganos. Revista de Processo, vol. 165, novembro, 2008 [recurso eletrônico].

${ }^{33}$ MITIDIERO, Daniel. Precedentes: da persuasão à vinculação. São Paulo: Revista dos Tribunais, 2016, p. 116.

${ }^{34}$ STRECK, Lenio; ABBOUD, Georges. O NCPC e os precedentes - afinal, do que estamos falando? In: DIDIER JÚNIOR, Fredie; et al. (coordenadores). Precedentes. Salvador: Juspodivm, 2015, p. 177.
} 
que o caso concreto que está sendo decidido não se amolda ao precedente invocado. Em razão da diferença dos fatos entre o caso decidido anteriormente (precedente) e aquele julgado no processo, não é possível transpor a razão de decidir de uma situação para a outra. ${ }^{35}$

Dessa maneira, se a analogia é um raciocínio necessário para justificar a aplicação de um precedente, o distinguishing funciona como uma contra-analogia na medida em que é o raciocínio inverso, ou seja, é a argumentação de que existe um distanciamento entre o caso concreto e a decisão paradigma. ${ }^{36}$

Com a finalidade de esclarecer os conceitos aqui delineados, não se pode confundir a técnica de distinção com a superação dos precedentes. ${ }^{37}$ A superação do precedente ocorre quando existe a necessidade de modificar o entendimento utilizado, pois este precisa permitir a evolução do Direito $^{38}$ e sua construção não tem o objetivo de durar para sempre.

Como bem observa Ravi Peixoto: “A adoção do stare decisis não significa, de forma alguma, o engessamento do direito. Existem diversas técnicas desenvolvidas pela jurisprudência e doutrina do common law, para além da própria interpretação dos precedentes, aptas a permitir um maior dinamismo na aplicação dos precedentes. A principal delas, para os fins deste trabalho, é o overruling, denominação atribuída à técnica de superação de um entendimento anterior sobre o mesmo objeto agora em julgamento; técnica que é essencial para qualquer sistema de precedentes, permitindo que o sistema possa evoluir. Ao contrário do que possa parecer, a superação dos precedentes, desde que utilizada com os devidos cuidados, promove o stare decisis, em vez de enfraquecê-lo, ao demonstrar

\footnotetext{
${ }^{35}$ LUCCA, Rodrigo Ramina de. O dever de motivação das decisões judiciais. Salvador: Juspodivm, 2015, p. 307. Nas palavras de Bruno Garcia Redondo: "Fala-se em distinguishing (ou distinguish) quando há diferença entre o caso concreto em exame e o paradigma anterior, seja porque inexiste coincidência com os fatos que a embasaram a ratio decidendi, seja porque, a despeito de eventual aproximação entre eles, há alguma peculiaridade no caso em julgamento que impõe a não aplicação do precedente". (REDONDO, Bruno Garcia. Aspectos essenciais da teoria geral do precedente judicial: identificação, interpretação, aplicação, afastamento e superação. Revista de Processo, vol. 217, mar., 2013)

${ }^{36}$ VIANA, Aurélio; NUNES, Dierle. Precedentes: a mutação do ônus argumentativo. Rio de Janeiro: Forense, 2018 , p. 383.

${ }^{37}$ JOBIM, Marco Félix. A técnica da distinguishing a partir da análise do julgamento do caso Escola vs. CocaCola Bottling Co. Revista de Processo, vol. 237, p. 403-419, nov., 2014 [recurso eletrônico]; FENSTERSEIFER, Wagner Arnold. Distinguinshing e overruling na aplicação do Art. 489, § $1^{\circ}$, VI, do CPC/2015. Revista de Processo, vol. 252, p. 371-385, São Paulo, fev., 2016 [recurso eletrônico].

${ }^{38}$ SILVA, Diego Bacha. Agravo interno como momento processual adequado para a distinção ou superação do precedente. Revista de Processo, vol. 250, p. 243-263, São Paulo, dez., 2015 [recurso eletrônico].
} 
que a existência de precedentes obrigatórios não significa impossibilidade de evolução do direito." 39

A distinção, por sua vez, implica determinar que o entendimento do precedente não pode ser aplicado ao caso concreto, porque as circunstâncias de fato são diferentes. Neste último, o precedente não é modificado, apenas não será aplicado para aquelas questões fáticas.

Ocorre que tal diferenciação entre um caso e outro deve ser relevante para o julgamento do caso concreto, ${ }^{40}$ pois pela teoria da identidade essencial não poderá ser aplicada a distinção quando as pequenas diferenças entre os casos não influenciarem no resultado do julgamento. No entanto, o problema ainda está em definir quando que uma diferença de um caso para outro irá influenciar no resultado do julgamento e, portanto, autorizar a aplicação da distinção, o que dependerá do cumprimento do ônus argumentativo das partes, dos tribunais de justiça estaduais ou federais e do Superior Tribunal de Justiça.

Aqui não há como negar a dimensão interpretativa do raciocínio por meio de precedentes judiciais, pois dizer que casos semelhantes devem ser julgados de forma semelhante não indica quando identificar ou como identificar os casos que são semelhantes. ${ }^{41}$ Por isso, a necessidade de trabalhar com a analogia.

Assim, tanto o distinguishing, quanto o confronto analítico apresentam a necessidade de utilização de um raciocínio analógico. Ao tratar sobre a analogia em relação à distinção de precedentes Carlos Edinger explica: “[...] a superação da analogia - a distinção de casos - é feita a partir da demonstração de que o princípio comum, a razão generalizável, não é aplicável ao caso concreto. Essa constatação reforça a ideia de que devamos compreender o raciocínio analógico não só como mero argumento a partir do exemplo, mas também, como expondo-nos ao golpe do interlocutor, explicitação da validade do critério relacional que subjaz o exemplo. Afinal, fatos irrelevantes não tornam casos desiguais. Em outras palavras, não basta afirmarmos que uma questão jurídica não é similar a outra. Cabe

\footnotetext{
${ }^{39}$ PEIXOTO, Ravi. Superação do precedente e segurança jurídica. Salvador: Juspodivm, 2015, p. 197.

${ }^{40}$ Idem. O sistema de precedentes desenvolvido pelo CPC/2015 - uma análise sobre a adaptabilidade da distinção (distinguishing) e da distinção inconsistente (inconsistent distiguishing). Revista de Processo, vol. 248, p. 331-355, São Paulo, out., 2015 [recurso eletrônico].

${ }^{41}$ STRECK, Lenio Luiz. Precedentes Judicias e Hermenêutica: o sentido da vinculação no CPC/2015. $2^{\mathrm{a}}$ ed. Salvador: Juspodivm, 2019, p. 98.
} 
a nós, analiticamente, demonstrarmos a relevância da distinção: a justificativa para não se seguir o precedente." 42

Por meio do raciocínio analógico empregado pelas técnicas da distinção e do confronto analítico, é possível comparar precedentes judiciais empregados pelos Tribunais de Justiça Estaduais e pelos Tribunais Regionais Federais e fundamentar tanto o recebimento, quanto o não recebimento do recurso especial pelo Superior Tribunal de Justiça, quando o fundamento do recurso especial for a divergência jurisprudencial.

Anteriormente, demonstrou-se que o precedente implica um ônus argumentativo na sua interpretação e aplicação. Na dinâmica do recurso especial fundamentado em divergência de precedentes, o recorrente assume o ônus argumentativo de demonstrar por meio do confronto analítico a semelhança fática entre o caso recorrido e o acórdão paradigma. A parte recorrida adotará em suas contrarrazões o ônus de explicar por que os casos não são semelhantes (distiguishing) e, portanto, o recurso deve ser inadmitido. $\mathrm{O}$ Tribunal de Justiça ou o Tribunal Regional Federal devem, como primeiro filtro de admissibilidade, explanar a realização do distinguishing quando a inadmissibilidade for reconhecida pelo tribunal com base nesse argumento. Por fim, o Superior Tribunal de Justiça também precisa fundamentar, de forma analítica, o juízo de admissibilidade ou inadmissibilidade do recurso especial a partir da distinção.

Nesse ponto, é importante notar que Art. 1.029 , $§ 2^{\circ}$ do $\mathrm{CPC} / 2015$ previa expressamente que, ao inadmitir um recurso especial fundado em "dissídio jurisprudencial", o STJ, o TRF e o TJ não poderiam lançar mão de argumentos genéricos, devendo utilizar a técnica da distinção para fundamentar a sua decisão. Tal previsão foi revogada pela Lei 13.256/2016, o que não significa que é possível justificar uma decisão de inadmissibilidade de forma genérica na medida em que o Art. $489, \S 1^{\circ}$ do $\mathrm{CPC} / 2015^{43}$ não foi revogado. Esse

\footnotetext{
${ }^{42}$ EDINGER, Carlos. Distinguishing: raciocínio analógico. Revista de Processo, vol. 266, p. 421-446, São Paulo, abr., 2017 [recurso eletrônico].

${ }^{43}$ Art. $489[\ldots]$

$\S 1^{\circ}$ Não se considera fundamentada qualquer decisão judicial, seja ela interlocutória, sentença ou acórdão, que:

I - se limitar à indicação, à reprodução ou à paráfrase de ato normativo, sem explicar sua relação com a causa ou a questão decidida;

II - empregar conceitos jurídicos indeterminados, sem explicar o motivo concreto de sua incidência no caso;

III - invocar motivos que se prestariam a justificar qualquer outra decisão;

IV - não enfrentar todos os argumentos deduzidos no processo capazes de, em tese, infirmar a conclusão adotada pelo julgador;
} 
dispositivo contém a obrigação de fundamentação analítica de todas as decisões judiciais, ${ }^{44}$ vedando fórmulas genéricas (incisos I e III) e demandando a utilização da distinção quando deixar de aplicar precedente judicial (V e VI). Segundo Carlos Edinger, é o dever de motivação que permite o controle dos critérios que serão utilizados para realizar a distinção ou identificar a igualdade entre os casos que estão sendo analisados. ${ }^{45}$

Em relação ao acórdão paradigma (utilizado para fazer a comparação entre os casos), é necessário que este seja prolatado por um tribunal diferente daquele em que o recurso especial está sendo interposto, ${ }^{46}$ incluindo-se aqui divergência entre precedente do próprio Superior Tribunal de Justiça e o acórdão recorrido. ${ }^{47}$ Requer-se também que a divergência seja atual, ${ }^{48}$ não sendo suficiente o confronto com um precedente que já tenha sido superado pelo tribunal de justiça. ${ }^{49}$

Por fim, a comprovação do acórdão paradigma é regulamentada pelo Art. 1029, $\S 1^{\circ}$ do CPC $/ 2015^{50}$ que admite tanto a utilização de repositório oficial ou credenciado pelo

\footnotetext{
V - se limitar a invocar precedente ou enunciado de súmula, sem identificar seus fundamentos determinantes nem demonstrar que o caso sob julgamento se ajusta àqueles fundamentos;

VI - deixar de seguir enunciado de súmula, jurisprudência ou precedente invocado pela parte, sem demonstrar a existência de distinção no caso em julgamento ou a superação do entendimento.

${ }^{44}$ BAHIA, Alexandre Melo Franco. Recursos extraordinários no STF e no STJ. $2^{\mathrm{a}}$ ed. Curitiba: Juruá, 2016, p. 163-164. Nas palavras de José Miguel Garcia Medina: "A nosso ver, não se admite que o recurso especial fundado no art. 105, III, c, da CF/1988 não seja conhecido sob o fundamento, genérico, de que as circunstâncias fáticas do caso diferem-se daquele apontado pelo recorrente como paradigma. $\mathrm{O} \S 2^{\circ}$ do art. 1.029 do CPC/2015, revogado pela Lei 13.246/2016, era expresso nesse sentido. A vedação à fundamentação genérica e a necessidade de demonstração da distinção para não se admitir o recurso especial, no caso, decorre, sobretudo da principiologia que deve ser observada por todos os juízes, ao lidar com hipóteses relacionadas a essa temática. Assim, a revogação do $\S 2^{\circ}$ do art. 1.029 pelo Lei 13.256/2016 não autoriza a prolação de decisão baseada em fundamento genérico, que não demonstre a existência da distinção (cf. art. 489, § $1^{\circ}$, VI do CPC/2015)". (MEDINA, José Miguel Garcia. Prequestionamento, repercussão geral da questão constitucional, relevância da questão federal: admissibilidade, processamento e julgamento dos recursos extraordinário e especial. $7^{a}$ ed. São Paulo: Revista dos Tribunais, 2017, p. 313).

${ }^{45}$ EDINGER, Carlos. Distinguishing: raciocínio analógico. Revista de Processo, vol. 266, p. 421-446, São Paulo, abr., 2017 [recurso eletrônico].

${ }^{46}$ BAHIA, Alexandre Melo Franco. Recursos extraordinários no STF e no STJ. $2^{\mathrm{a}}$ ed. Curitiba: Juruá, 2016, p. 163.

${ }^{47}$ TEIXEIRA, Sálvio de Figueiredo. O recurso especial e o Superior Tribunal de Justiça. Doutrinas Essenciais de Processo Civil, Vol. 7, p. 347-360, São Paulo, out., 2011 [recurso eletrônico].

${ }^{48}$ BRUSCHI, Gilberto Gomes. Recurso especial fundado em divergência jurisprudencial. Revista de Processo, vol. 148, p. 119-133, São Paulo, jun., 2007 [recurso eletrônico].

${ }^{49}$ TEIXEIRA, Sálvio de Figueiredo. O recurso especial e o Superior Tribunal de Justiça. Doutrinas Essenciais de Processo Civil, Vol. 7, p. 347-360, São Paulo, out., 2011 [recurso eletrônico].

50 “Art. $1.029[\ldots] \S 1^{\circ}$ Quando o recurso fundar-se em dissídio jurisprudencial, o recorrente fará a prova da divergência com a certidão, cópia ou citação do repositório de jurisprudência, oficial ou credenciado, inclusive em mídia eletrônica, em que houver sido publicado o acórdão divergente, ou ainda com a reprodução de julgado disponível na rede mundial de computadores, com indicação da respectiva fonte, devendo-se, em qualquer caso, mencionar as circunstâncias que identifiquem ou assemelhem os casos confrontados."
} 
$\mathrm{STJ}^{51}$ (a partir de certidão, cópia ou citação) quanto à reprodução do precedente por meio da internet, devendo, neste último caso, indicar a fonte em que foi encontrado.

\section{O POSICIONAMENTO DO SUPERIOR TRIBUNAL DE JUSTIÇA}

\subsection{Restrição do Acórdão Paradigma em Ações Mandamentais}

O primeiro julgado a ser analisado trata de um Agravo Regimental em um Agravo em Recurso Especial (n. ${ }^{\circ}$ 596.663-MG) que buscava a nulidade de uma condenação penal. Em um processo com dois corréus, um teve a sua condenação anulada por ausência de apresentação de resposta à acusação enquanto o segundo teve a condenação mantida.

Assim, o corréu condenado buscava estender a anulação para o seu acórdão condenatório. Ao fundamentar o recurso especial, o recorrente utilizou como acórdãos paradigmas decisões proferidas em sede de habeas corpus.

Nesse ponto, o Relator Min. Jorge Mussi fundamentou a sua decisão alegando que ações mandamentais da estirpe de habeas corpus e mandado de segurança não podem ser utilizados como decisões paradigmas "em razão de tais remédios possuírem objetos e naturezas distintas do recurso especial, além de não apresentarem a mesma extensão material quando comparadas ao apelo nobre". ${ }^{52}$ Para sustentar sua oposição, o Relator colaciona três ementas de julgados proferidos no âmbito do STJ referentes aos recursos: AgRg no REsp 1469363/GO de 02/10/2014; AgRg nos EREsp 998.249/RS de 21/09/20012; AgRg no REsp 1329137/RS de 14/10/2013.

Aqui cabem duas considerações, a primeira diz respeito à forma de fundamentação jurídica da questão na medida em que o Relator, ao justificar a sua decisão a partir de julgados pretéritos (precedentes), não realizou a comparação fática e jurídica entre

\footnotetext{
${ }^{51}$ Os repositórios oficiais e autorizados estão previstos no Art. $255, \S 3^{\circ}$ do Regimento Interno do STJ: “ $\S 3^{\circ}$ São repositórios oficiais de jurisprudência, para o fim do $\S 1^{\circ}$ deste artigo, a Revista Trimestral de Jurisprudência do Supremo Tribunal Federal, a Revista do Superior Tribunal de Justiça e a Revista do Tribunal Federal de Recursos e, autorizados ou credenciados, os habilitados na forma do art. 134 e seu parágrafo único deste Regimento".

52 BRASIL. Superior Tribunal de Justiça. AgRg no AREsp 596.663/MG. Rel. Ministro Jorge Mussi, DJe 21/03/2018. No mesmo sentido: BRASIL. Superior Tribunal de Justiça. AgRg no AREsp 1527547/PR. Rel. Ministro Antonio Saldanha Palheiro, DJe 02/12/2019.
} 
o caso em exame e os precedentes judiciais que foram invocados, o que viola frontalmente sua forma de interpretação e aplicação. Como visto, a ementa não é precedente.

A segunda consideração é concernente ao argumento utilizado para excluir decisões colegiadas em sede de habeas corpus e mandado de segurança da categoria de acórdãos paradigmas que podem ser utilizadas para demonstrar a divergência de precedentes

judiciais. É certo que essas ações possuem características próprias que limitam o seu âmbito de atuação e a sua forma de produção probatória. Por outro lado, a partir do momento em que se compreende a utilização do confronto analítico e da distinção como forma de comparação de casos que indicam ou não a similaridade de precedentes judiciais criados por tribunais diferentes, sustentar que habeas corpus e mandado de segurança não podem ser usados é dizer que decisões colegiadas nessas ações não servem para formar precedentes.

Assim, percebe-se que a restrição na utilização desse tipo de decisão judicial é uma verdadeira jurisprudência defensiva que realiza limitações que não estão previstas em lei. O que vai determinar se as decisões em sede de habeas corpus ou mandado de segurança podem ser utilizadas como acórdãos paradigmas não é a sua natureza ou extensão, mas a similitude dos fatos e a divergência de interpretação do dispositivo da legislação federal. A inadmissão do recurso especial deve ser realizada por meio do distinguishing e não pela natureza ou objeto do acórdão paradigma.

\subsection{Dissídio Notório e Flexibilização do Confronto Analítico}

Importante questão estabelecida pelo Superior Tribunal de Justiça é que, quando a divergência do acórdão recorrido for notória em relação ao posicionamento do próprio STJ, fica flexibilizado o requisito de confronto analítico. Tal posicionamento pode ser encontrado em diversos julgados do tribunal, ${ }^{53}$ contudo geralmente fundamentados de forma superficial (ementismo) em julgados anteriores o que dificulta identificar a razão de decidir que levou à construção dessa jurisprudência.

\footnotetext{
${ }^{53}$ BRASIL. Superior Tribunal de Justiça. AgInt no AREsp 144.608/RJ. Rel. Ministra Maria Isabel Gallotti, DJe 22/08/2017; BRASIL. Superior Tribunal de Justiça. REsp 1653169/RJ. Rel. Ministra Regina Helena Costa, DJe 11/12/2019; BRASIL. Superior Tribunal de Justiça. AgInt no REsp 1814187/RS. Rel. Ministro Marco Aurélio Bellizze, DJe 22/10/2019.
} 
O primeiro julgado do STJ a respeito do assunto data do ano de 1990. Sob a relatoria do Min. Sálvio de Figueiredo Teixeira, o Resp. 2122/MS ${ }^{54}$ trata da possibilidade de correção monetária nos empréstimos rurais. Por versar acerca de um problema notório da época em que a inflação chegava a $80 \%$ ao mês, o Relator entendeu que não seria necessária a realização do cotejo analítico para admitir o recurso especial pelo Art. 105, III, c da CF/88. Fundamenta a sua decisão no imperativo de que o Superior Tribunal de Justiça possui a missão de uniformizar o "direito federal” e garantir a segurança jurídica.

Em outro julgado, o Min. Sálvio de Figueiredo Teixeira complementa o seu raciocínio afirmando que fatos notórios não precisam de prova, por isso a divergência notória também não requer tal comprovação. Assim, mesmo que exista apenas a transcrição da ementa, esta será suficiente em caso de manifesta divergência de jurisprudência. Se a missão do STJ é uniformizar a interpretação da lei federal, este não pode se restringir a questões formais quando isso o impedir de cumprir a sua função. ${ }^{55}$ Com esse raciocínio, o Relator também entendeu ser possível conhecer do recurso especial quando o dissídio notório for caracterizado pelo desrespeito à súmula do STJ e o recorrente fizer a comparação por meio de acórdão paradigma colhido em repositório não autorizado pelo tribunal. ${ }^{56}$

Assim, a partir desses primeiros julgados, passou-se a repetir que a jurisprudência do STJ estaria pacificada no sentido de flexibilizar o confronto analítico diante de dissídio jurisprudencial notório. ${ }^{57} \mathrm{O}$ que não pode deixar de ser criticável na medida em que tal posicionamento passou a ser sustentado sem nenhuma remissão às hipóteses que podem gerar o chamado "dissídio jurisprudencial notório" nem às razões de decidir que fundamentam esse entendimento.

\subsection{A Contradição do Superior Tribunal de Justiça na Argumentação em Relação a Precedentes}

\footnotetext{
${ }^{54}$ BRASIL. Superior Tribunal de Justiça. REsp 2.122/MS. Rel. Ministro Sálvio de Figueiredo Teixeira, DJ 11/06/1990, p. 5361.

${ }^{55}$ BRASIL. Superior Tribunal de Justiça. EDcl nos EDcl no REsp 9.035/MG. Rel. MIN. Sálvio de Figueiredo Teixeira, DJ 01/02/1993, p. 464.

${ }^{56}$ BRASIL. Superior Tribunal de Justiça. REsp 41.731/RN. Rel. Ministro Sálvio de Figueiredo Teixeira, DJ 23/05/1994, p. 12614.

57 Veja-se, por exemplo: BRASIL. Superior Tribunal de Justiça. REsp 121.429/SP. Rel. Ministro Francisco Peçanha Martins, DJ 09/11/1998, p. 62.
} 
O último ponto que merece destaque é a contradição na forma que se exige a comparação analítica entre precedentes no cabimento do recurso especial ao mesmo tempo em que o Superior Tribunal de Justiça se utiliza de "ementismo" para aplicar precedentes e proferir o seu julgamento.

Já ficou demonstrado que o confronto analítico exige a demonstração da similitude fática e a divergência de interpretação de um mesmo dispositivo de legislação federal. Isso porque é preciso comprovar que o precedente invocado de outro tribunal foi o que concedeu a melhor interpretação para o caso concreto. Todo o raciocínio desenvolvido na argumentação é um raciocínio próprio da aplicação de precedentes judiciais e a jurisprudência do STJ exige que esse ônus argumentativo seja cumprido pelo recorrente, salvo nos casos de dissídio notório.

Ocorre que essa forma de argumentação deve ser utilizada em toda aplicação de precedentes judiciais. $\mathrm{O}$ art. $489, \S 1^{\circ}$, V do CPC $2015^{58}$ exige a fundamentação analítica sempre que precedente ou súmula forem invocados para decidir. Portanto, existe também um ônus argumentativo do Superior Tribunal de Justiça no momento de utilizar seus precedentes para fundamentar as decisões judiciais. Não é aceitável que o ônus argumentativo seja distribuído apenas para as partes no momento de fundamentar o recurso especial, pois, em uma perspectiva democrática e cooperativa, o Poder Judiciário também deve assumir a sua função na consolidação do sistema de precedentes judiciais brasileiro.

A distribuição do ônus argumentativo na interpretação e aplicação de precedentes judiciais é explicada por Aurélio Viana e Dierle Nunes: "Se o juiz é obrigado a observar o dever de fundamentação analítica (art. 489), as parte devem fazer o mesmo, de tal modo que o advogado do autor, por exemplo, ao exercer a pretensão em juízo, não pode se limitar a fazer a mera indicação, a reprodução ou a paráfrase de ato normativo sem explicar sua relação com a causa ou a questão decidida [...]. ${ }^{59}$

Existem diversos julgados no âmbito do STJ que negam o seguimento ao recurso especial em razão da parte não demonstrar a similitude fática ou a divergência de

\footnotetext{
${ }^{58}$ Art. 489 [...]

$\S 1^{\circ}$ Não se considera fundamentada qualquer decisão judicial, seja ela interlocutória, sentença ou acórdão, que: $[\ldots]$

V - se limitar a invocar precedente ou enunciado de súmula, sem identificar seus fundamentos determinantes nem demonstrar que o caso sob julgamento se ajusta àqueles fundamentos;

${ }^{59}$ VIANA, Aurélio; NUNES, Dierle. Precedentes: a mutação do ônus argumentativo. Rio de Janeiro: Forense, 2018 , p. 395.
} 
interpretação de dispositivo da legislação federal ao mesmo tempo que fundamentam sua decisão invocando ementas como se fossem precedentes. ${ }^{60}$

Tais condutas, além de representarem casos de nulidade por falta de fundamentação analítica, demonstram que o STJ não está atento para as mudanças que são necessárias a fim de que os precedentes judiciais possam ser formados, interpretados e aplicados. Isso reforça a nossa concepção de que o precedente não vincula em razão da sua genealogia, pois sua força é construída a partir de sua utilização posterior pelos sujeitos processuais. Julgados que não são devidamente fundamentados não têm um requisito mínimo para se tornarem precedentes, ou seja, sem assumir a sua parte no ônus argumentativo, o tribunal não possui a envergadura necessária para que seus julgamentos sejam aplicados como verdadeiros precedentes judiciais.

\section{CONCLUSÃO}

Ao longo do texto, foi possível discutir e concluir que os precedentes judiciais são formados a partir da sua interpretação e aplicação. O precedente representa um princípio de argumentação para fundamentar decisões posteriores. Sua importância argumentativa é derivada de sua utilização posterior pelo mesmo tribunal ou por tribunais inferiores e não apenas pelo fato de serem originários dos tribunais superiores. Esses tribunais devem julgar os casos e não teses jurídicas.

Apesar de assumirem a função de uniformizar a interpretação da legislação federal, os recursos extraordinários (recurso especial e recurso extraordinário em sentido estrito) não podem assumir uma função totalmente pública e utilizarem casos simplesmente como um "pretexto" para fixar teses de julgamento. Até porque a aplicação posterior dos julgados como precedentes dependerá de uma análise fática e jurídica.

Em relação ao recurso especial, demonstrou-se que é a argumentação em torno de precedentes que permite falar em confronto analítico e distinção para a análise do cabimento quando houver divergência entre decisões de tribunais diferentes. O confronto

\footnotetext{
${ }^{60}$ BRASIL. Superior Tribunal de Justiça. REsp 1726191/RS. Rel. Ministro Herman Benjamin, DJe 19/12/2019; BRASIL. Superior Tribunal de Justiça. AgRg nos EREsp 1770254/SP. Rel. Ministro Antonio Saldanha Palheiro, DJe 19/12/2019; BRASIL. Superior Tribunal de Justiça. AgInt no REsp 1825639/PR. Rel. Ministra Regina Helena Costa, DJe 18/12/2019; BRASIL. Superior Tribunal de Justiça. AgRg nos EREsp 1357289/PR. Rel. Ministro Sebastião Reis Júnior, DJe 16/12/2019.
} 
analítico representa um típico raciocínio analógico da aplicação de precedentes judicias, pois determina a comparação fática entre os casos em exame. Por outro lado, a distinção representa um raciocínio contrário à analogia, haja vista que é a forma de demonstrar que os casos não são semelhantes e o acórdão paradigma não pode ser utilizado para representar a divergência.

Por fim, sem a intenção de esgotar a pesquisa em torno de decisões do STJ, chegou-se à conclusão que o ônus argumentativo do raciocínio por precedentes tem sido relegado, de uma maneira geral, apenas para as partes recorrente e recorrida. O STJ, por sua vez, não tem atuado com o devido cuidado na fundamentação de suas decisões que utilizam precedentes judiciais. Isso prejudica a futura identificação dos elementos fáticos e jurídicos que embasaram a decisão e impossibilita a sua aplicação como razão de decidir em julgamentos futuros.

\section{REFERÊNCIAS}

ABBOUD, Georges. Do genuíno precedente do stare decisis ao precedente brasileiro: os fatores histórico, hermenêutico e democrático que os diferenciam. In: DIDIER JÚNIOR, Fredie; et al. (coordenadores). Precedentes. Salvador: Juspodivm, 2015.

ALVIM, Teresa Arruda; DANTAS, Bruno. Recurso especial, recurso extraordinário e a nova função dos tribunais superiores no direito brasileiro. $4^{\mathrm{a}}$ ed. São Paulo: Revista dos Tribunais, 2017.

BAHIA, Alexandre Melo Franco. Recursos extraordinários no STF e no STJ. $2^{\mathrm{a}}$ ed. Curitiba: Juruá, 2016.

. As súmulas vinculantes e a nova Escola da Exegese. Revista de Processo, ano 37, vol. 206, p. 359-379, abril, 2012.

BRASIL. Superior Tribunal de Justiça. AgInt no AREsp 144.608/RJ. Rel. Ministra Maria Isabel Gallotti, DJe 22/08/2017.

Superior Tribunal de Justiça. AgInt no REsp 1814187/RS. Rel. Ministro Marco Aurélio Bellizze, DJe 22/10/2019.

Superior Tribunal de Justiça. AgInt no REsp 1825639/PR. Rel. Ministra Regina Helena Costa. DJe 18/12/2019. 
. Superior Tribunal de Justiça. AgRg no AREsp 1527547/PR. Rel. Ministro Antonio

Saldanha Palheiro, DJe 02/12/2019.

. Superior Tribunal de Justiça. AgRg no AREsp 596.663/MG. Rel. Ministro Jorge

Mussi, DJe 21/03/2018.

- Superior Tribunal de Justiça. AgRg nos EREsp 1357289/PR. Rel. Ministro

Sebastião Reis Júnior, DJe 16/12/2019.

. Superior Tribunal de Justiça. AgRg nos EREsp 1770254/SP. Rel. Ministro Antonio

Saldanha Palheiro, DJe 19/12/2019.

. Superior Tribunal de Justiça. EDcl nos EDcl no REsp 9.035/MG. Rel. MIN. Sálvio

de Figueiredo Teixeira, DJ 01/02/1993, p. 464.

. Superior Tribunal de Justiça. REsp 121.429/SP. Rel. Ministro Francisco Peçanha

Martins, DJ 09/11/1998, p. 62.

. Superior Tribunal de Justiça. REsp 1653169/RJ. Rel. Ministra Regina Helena Costa,

DJe 11/12/2019.

. Superior Tribunal de Justiça. REsp 1726191/RS. Rel. Ministro Herman Benjamin,

DJe 19/12/2019.

. Superior Tribunal de Justiça. REsp 2.122/MS. Rel. Ministro Sálvio de Figueiredo

Teixeira, DJ 11/06/1990, p. 5361.

. Superior Tribunal de Justiça. REsp 41.731/RN. Rel. Ministro Sálvio de Figueiredo

Teixeira, DJ 23/05/1994, p. 12614.

BRUSCHI, Gilberto Gomes. Recurso especial fundado em divergência jurisprudencial.

Revista de Processo, vol. 148, p. 119-133, São Paulo, jun., 2007 [recurso eletrônico].

Disponível em: www.revistadostribunais.com.br. Acesso em: 02.10.2017.

CARNEIRO, Athos Gusmão. Anotações sobre o recurso especial. Doutrinas Essenciais de Processo Civil, Vol. 7, p. 361-374, São Paulo, out., 2011 [recurso eletrônico]. Disponível em: www.revistadostribunais.com.br. Acesso em: 02.10.2017.

COLE, Charles D. Stare decisis na cultura jurídica dos Estados Unidos. O sistema de precedente vinculante no common law. Revista dos Tribunais. Vol. 752, p. 11-18, São Paulo, jun., 1998 [recurso eletrônico]. Disponível em: www.revistadostribunais.com.br. Acesso em: 10.05.2017. 
DIDIER JÚNIOR, Fredie; CUNHA, Leonardo Carneiro da. Curso de direito processual civil: meios de impugnação às decisões e processo nos tribunais. $13^{\mathrm{a}}$ ed. Salvador: Juspodivm, 2016.

EDINGER, Carlos. Distinguishing: raciocínio analógico. Revista de Processo, vol. 266, p. 421-446, São Paulo, abr., 2017 [recurso eletrônico]. Disponível em: www.revistadostribunais.com.br. Acesso em: 09.10.2017.

FENSTERSEIFER, Wagner Arnold. Distinguinshing e overruling na aplicação do Art. 489, $\S 1^{\circ}$, VI, do CPC/2015. Revista de Processo, vol. 252, p. 371-385, São Paulo, fev., 2016 [recurso eletrônico]. Disponível em: www.revistadostribunais.com.br. Acesso em: 09.10.2017.

JOBIM, Marco Félix. A técnica da distinguishing a partir da análise do julgamento do caso Escola vs. Coca-Cola Bottling Co. Revista de Processo, vol. 237, p. 403-419, nov., 2014 [recurso eletrônico].

LOPES FILHO, Juraci Mourão. Os precedentes judiciais no constitucionalismo brasileiro contemporâneo. $2^{\mathrm{a}}$ ed. Salvador: Juspodivm, 2016.

LUCCA, Rodrigo Ramina de. O conceito de precedente judicial, ratio decidendi e a universalidade das razões jurídicas de uma decisão. In: NUNES, Dierle; MENDES, Aluisio; JAYME, Fernando Gonzaga (org.). A nova aplicação da jurisprudência e precedentes no CPC/2015. São Paulo: Revista dos Tribunais, 2017.

. O dever de motivação das decisões judiciais. Salvador: Juspodivm, 2015.

MAGALHÃES, Breno Baía; SILVA, Sandoval Alves da. Quem vê ementa, não vê precedente: ementismo e precedentes judiciais no projeto do CPC. In: FREIRE, Alexandre; et all (org.) Novas tendências do processo civil: estudos sobre o projeto do novo Código de Processo Civil. Salvador: Juspodivm, 2014. V. II.

MARINONI, Luiz Guilherme. O STJ enquanto cortes de precedentes. $2^{\mathrm{a}}$ ed. São Paulo: Revista dos Tribunais, 2014.

MEDINA, José Miguel Garcia. Prequestionamento, repercussão geral da questão constitucional, relevância da questão federal: admissibilidade, processamento e julgamento dos recursos extraordinário e especial. $7^{\text {a }}$ ed. São Paulo: Revista dos Tribunais, 2017. 
MITIDIERO, Daniel. Cortes Superiores e Cortes Supremas: do controle à interpretação, da jurisprudência ao precedente. $3^{\text {a }}$ ed. São Paulo: Revista dos Tribunais, 2017,

Precedentes, jurisprudência e súmulas no novo Código de Processo Civil brasileiro. Revista de Processo, vol. 245, p. 333-349, julho, 2015 [recurso eletrônico].

. Precedentes: da persuasão à vinculação. São Paulo: Revista dos Tribunais, 2016.

NUNES, Dierle; Bahia, Alexandre; PEDRON, Flávio Quinaud. Teoria geral do processo. Salvador: Juspodivm, 2020.

PEIXOTO, Ravi. O sistema de precedentes desenvolvido pelo CPC/2015 - uma análise sobre a adaptabilidade da distinção (distinguishing) e da distinção inconsistente (inconsistent distiguishing). Revista de Processo, vol. 248, p. 331-355, São Paulo, out., 2015 [recurso eletrônico]. Disponível em: www.revistadostribunais.com.br. Acesso em: 02.10.2017.

. Superação do precedente e segurança jurídica. Salvador: Juspodivm, 2015.

REDONDO, Bruno Garcia. Aspectos essenciais da teoria geral do precedente judicial: identificação, interpretação, aplicação, afastamento e superação. Revista de Processo, vol. 217, mar., 2013.

SILVA, Diego Bacha. Agravo interno como momento processual adequado para a distinção ou superação do precedente. Revista de Processo, vol. 250, p. 243-263, São Paulo, dez., 2015 [recurso eletrônico]. Disponível em: www.revistadostribunais.com.br. Acesso em: 09.10.2017.

STRECK, Lenio Luiz. Precedentes Judicias e Hermenêutica: o sentido da vinculação no CPC/2015. 2 ${ }^{\text {a }}$ ed. Salvador: Juspodivm, 2019.

; ABBOUD, Georges. O NCPC e os precedentes - afinal, do que estamos falando? In: DIDIER JÚNIOR, Fredie; et al. (coordenadores). Precedentes. Salvador: Juspodivm, 2015.

TARUFFO, Michele. Precedente e jurisprudência. Revista de Processo. Vol. 29, p. 199-208, São Paulo, set., 2011 [recurso eletrônico]. Disponível em: Www.revistadostribunais.com.br. Acesso em: 10.05.2017.

TEIXEIRA, Sálvio de Figueiredo. O recurso especial e o Superior Tribunal de Justiça. Doutrinas Essenciais de Processo Civil, Vol. 7, p. 347-360, São Paulo, out., 2011 
[recurso eletrônico]. Disponível em: www.revistadostribunais.com.br. Acesso em: 02.10.2017.

VIANA, Aurélio; NUNES, Dierle. Precedentes: a mutação do ônus argumentativo. Rio de Janeiro: Forense, 2018.

WEBER, Márcia Regina Lusa Cadore. Anotações sobre os recursos especial e extraordinário. Revista dos Tribunais, Vol. 820, p. 98-124, São Paulo, Fev., 2004 [recurso eletrônico]. Disponível em: www.revistadostribunais.com.br. Acesso em: 02.10.2017.

ZANETI JR., Hermes. O valor vinculante dos precedentes: teoria dos precedentes normativos formalmente vinculantes. $2^{\mathrm{a}}$ ed. Salvador: Juspodivm, 2016. . Precedentes (treat like cases alike) e o novo Código de Processo Civil: universalização e vinculação horizontal como critérios de racionalidade e a negação da "jurisprudência persuasiva" como base para uma teoria dogmática dos precedentes no Brasil. Revista de Processo, vol. 235, p. 293-349, set., 2014 [recurso eletrônico]. 